\title{
Bilinçli Farkındalık ve Algılanan Stres İlişkisinde Ruminasyon ve Olumsuz Duygu Düzenlemenin Aracı Rolü*
}

\author{
The Mediatory Role of Rumination and Negative Mood \\ Regulation in The Relationship Between Mindfulness and \\ Perceived Stress
}

\author{
Fulya CENKSEVEN ÖNDER**, Çağrı UTKAN***
}

\begin{abstract}
Öz: Araştırmada üniversite öğrencilerinin bilinçli farkındalıkları ile algıladıkları stres arasındaki ilişkide ruminasyon ve olumsuz duygudurum düzenlemenin aracılık rolünü incelemek amaçlanmıştır. Araştırma 425'i kadın (\%57) ve 320'si erkek (\%43) olmak üzere toplam 745 üniversite öğrencisi üzerinde gerçekleştirilmiştir. Öğrencilerin yaş ortalaması 21.64'dür ( $\mathrm{Ss}=2.77)$. Araştırmada "Bilinçli Farkındalık Ölçeği”," "Algılanan Stres Ölçeği”, "Ruminatif Düşünme Biçimi Ölçeğì” ve "Olumsuz Duygudurum Düzenlemesi Ölçeği” kullanılmıştır. Aracılık analizlerinde regresyon temelli aracılık makrosu kullanılmıştır. Dolaylı etkilerin anlamlılı̆ını incelemek için hem Sobel Z, hem de bootstrapping prosedürü kullanılmıştır. Araştırma sonucunda Sobel $Z$ testi ve bootstrapping sonuçları hem ruminasyonun $(\mathrm{Z}=-6.99, \mathrm{p}<.001$, Bootstrap katsayıs $=-.06, \mathrm{Sh}=.01, \% 95 \mathrm{GA}=-.09,-04)$ hem de olumsuz duygudurum düzenlemenin $(\mathrm{Z}=-6.99, \mathrm{p}<.001$, Bootstrap katsayıs1 $=-.09, \mathrm{Sh}=.01, \% 95 \mathrm{GA}=-$ .12 , -07) bilinçli farkındalık ve algılanan stres arasındaki ilişkide kısmi aracı role sahip olduğunu göstermiştir.

Anahtar Kelimeler: Bilinçli farkındalık, stres, ruminasyon, olumsuz duygu düzenleme, duygudurum düzenleme
\end{abstract}

\begin{abstract}
The study aims to examine the mediatory role of rumination and negative mood regulation in the relationship between mindfulness and perceived stress among university students. The study sample consisted of 745 university students, 425 of whom were female $(57 \%)$ and 320 of whom were male $(43 \%)$. The age average of the participant students is 21.64 ( $\mathrm{Sd}=2.77)$. The Mindful Attention Awareness Scale, Perceived Stress Scale, Ruminative Thought Style Questionnaire and The Negative Mood Regulation Scale were used in the study. For mediatory analysis, a regression-oriented mediatory macro technique was employed. Both Sobel $\mathrm{Z}$ and bootstrapping procedures were applied to analyze the significance of indirect effects. The study results related to Sobel $\mathrm{Z}$ and bootstrapping procedures demonstrated that both rumination $(\mathrm{Z}=-6.99, \mathrm{p}<.001$, Bootstrap coefficient $=-.06, \mathrm{Sh}=.01,95 \% \mathrm{GA}=-$ $.09,-04)$ and negative mood regulation $(\mathrm{Z}=-6.99, \mathrm{p}<.001$, Bootstrap coefficient $=-.09, \mathrm{Sh}=.01,95 \% \mathrm{GA}=$ $-.12,-07)$ partially mediated between mindfulness and perceived stress.
\end{abstract}

Keywords: Mindfulness, stress, rumination, negative mood regulation, mood regulation

\section{Giriş}

Stres içeriden veya dişarıdan gelerek bireyin var olan denge halini veya duygusal, bilişsel, sosyal fonksiyonlarını bozma eğilimi gösteren; kişiyi mevcut denge durumunu korumaya veya bozulmuş olan denge halini yeniden sağlamaya yönelik yeni davranışlar sergilemeye zorlayan, gerçek veya algılanan uyarıcılara verdiği bilişsel, ruhsal veya fiziksel tepkiler olarak adlandırılmaktadır (Budak, 2001). Son yıllarda strese neden olduğu düşünülen olayların kişi üzerindeki etkisinin, bireyin bu olayı stres verici olarak bulup bulmadığına bağlı olarak

\footnotetext{
* Bu makale 12-14 Mayıs 2017 tarihlerinde İstanbul'da gerçekleştirilen 2. Avrasya Pozitif Psikoloji Kongresi'nde kabul edilen sözel bildirinin genişletilmiş halidir.

** Doç. Dr., Çukurova Üniversitesi, Eğitim Fakültesi, Adana, Türkiye, ORCID: 0000-0001-9748-626X, e-posta: fulyac@cu.edu.tr

*** Uzman Psikolojik Danışman, İl Milli Eğitim Müdürlüğü, Adana, Türkiye, ORCID: 0000-0003-2037-5937, eposta: cagriutkann@gmail.com
} 
değişebildiği görüşü yaygın bir biçimde kabul görmektedir (Yerlikaya ve İnanç, 2007). Bu bağlamda kişinin yaşadığı stresin düzeyini, kendisi için aşırı yüklü ve kontrol edilemez olarak değerlendirme derecesini ifade eden algılanan stres kavramı ön plana çıkmaktadır (Cohen, Kamarck ve Mermelstein, 1983).

Psikoloji alanında stres üzerinde yapılan kavramsallaştırmalarda stresin; uyaran, tepki ve etkileşim yönelimli olmak üzere üç farklı bağlamda ele alındığı görülmektedir (Yerlikaya, 2009). Uyaran yönelimli yaklaşım, stresi zorlanmaya neden olan, organizmaya zarar vererek denge ve düzenini bozan bütün sosyal, fiziksel ve psikolojik uyaranlar olarak tanımlanmaktadır. Bu yaklaşım 1950'li yıllarda Selye tarafından stresin "organizmaya zarar veren uyaran" olarak tanımlamasına dayanmaktadır. Tepki yönelimli yaklaşımda ise stres, var olan stresörlere karşı gösterilen psikolojik ve bedensel tepkiler olarak ele alınmaktadır. Bu görüşü Cannon (1932), organizmanın yaşamını devam ettirmesini ve çevreye uyum sağlamasını tehdit eden bir uyarıcıya yönelik sergilediği savaşma ve kaçma tepkisi olarak tanımlamıştır. Bazı araştırmacılar ise uyaran ve tepki yönelimli stres yaklaşımını tek başına yetersiz bulmuş ve stresi birey ile çevre arasında gerçekleşen bir süreç olarak ele almışlardır. Başka bir ifadeyle; kişisel alg1 ve değerlendirmelerimiz, kişi ve çevresi arasındaki etkileşimin sıkıntı verici olup olmayacağını belirleyen ana etkendir (Lazarus ve Folkman, 1984).

Yaşanan stres karşısında verilen en yaygın tepkiler öfke, üzüntü ve kaygı gibi olumsuz duygulardır. Bu nedenle stresle başa çıkmak için çeşitli yöntemler kullanılmaktadır. Stresle başa çıkma temelde yaşanan olumsuz sonuçları yok ederek veya azaltarak stresi olumlu seviyede tutabilmeyi tanımlamaktadır. Bu bağlamda stresle başa çıkmadaki temel amacın yaşanan olumsuz sonuçlardan korunmak olduğu söylenebilir (Şahin, 1994). Lazarus ve Folkman (1984) stresle başa çıkmaya yönelik olarak; yaşanan problemi çeşitli şekillerde çözme çabalarını kapsayan "problem merkezli başa çıkma" ile stres sonucu ortaya çıkan olumsuz (nahoş) duyguları yönetmeyi kapsayan "duygu merkezli başa çıkma" modelini önermişlerdir. Bu iki başa çıkma modeli birbiriyle ilişkili iki yönlü bir modeldir. Problem merkezli başa çıkma çabası; stresli durumun etkisini azaltmak, önlemek veya değiştirmek için doğrudan harekete geçmeyi içerirken, duygu merkezli baş etme stres sonucunda ortaya çıkan olumsuz duyguları kontrol altına alarak olumlu bir yöne odaklamaya yönelik davranış kalıplarını içermektedir.

Stres ve stres durumu ile başa çıkmayla ilgili olarak öne çıkan kavramlardan birisi de bilinçli farkındalıktır (Kabat-Zinn, 2009). Bilinçli farkındalık, kişinin dikkatini anlık, içsel ve çevresel deneyimlere yargısız bir biçimde yönlendirmesi (Kabat-Zinn, 2003) veya geçmişte yaşanmış veya gelecekte planlanan olası deneyim ve duyguların etkisi altında olmadan anlık deneyimleri yaşayarak an'ı kabul etmesi (Bishop ve diğerleri, 2004) olarak tanımlanmaktadır. Son yıllarda bilinçli farkındalık ile ilgili yapılan araştırmaların artmasına karşın bu kavramın temelleri yaklaşık olarak 2500 yıl öncesine, Budist felsefe ve bu yaklaşımda kullanılan meditasyon uygulamalarına kadar dayanmaktadır (Ögel, 2012). Alanyazında bilinçli farkındalık ile ilgili birbirinden farklı tanımlamalar olsa da özet olarak bu kavramın; şimdiye odaklı dikkat, kabullenme, yargısızlık ve içsel gözlem gibi temel birleşenlere sahip olduğu görülmektedir (Çatak ve Ögel, 2010).

Bilinçli farkındalık kavramı pozitif psikolojide öz-anlayış (compassion) kavramının öğelerinden birisi olarak ele alınmaktadır (Neff, 2003). Bilişsel-davranışçı kuram açısından bakıldığında ise özellikle üçüncü dalga bilişsel-davranışçı psikoterapilerin kabullenme ve farkındalık kavramlarını psikoterapinin merkezine almaya başladığı görülmektedir. Farkındalık Temelli Bilişsel Terapi, Kabullenme ve Kararlılık Terapisi ve Diyalektik Davranış Terapisi gibi Bilişsel-Davranışçı Psikoterapi Yaklaşımlanı buna örnek olarak verilebilir (Ögel, 2012). Bilinçli farkındalık temelli müdahaleler; depresyon (Morgan, 2003), panik bozukluk (Kim, Lee ve diğerleri, 2009), yaygın anksiyete bozukluğu (Kim, Lee ve diğerleri, 2009), kronik ağrı (KabatZinn, 1982), madde bağımlılığı (Leigh, Bowen ve Marlatt, 2005), sosyal kayg1 (Goldin ve Gross, 2010), onkolojik hastalıklar (Ott, Norris ve Bauer-Wu, 2006), yeme bozuklukları (Kristeller ve Wolever, 2010), psikozlar (Jacobsen, Morris, Johns ve Hodkinson, 2011), stres (Grossman, Niemann, Schmidt ve Walach, 2004), çift terapisi (Hayes, 2004), borderline kişilik 
bozukluğu (Wupperman, Neumann ve Axelrod, 2008) gibi birçok farklı alanda başarılı bir biçimde kullanılmaktadır.

Yurt dışında yapılan çalışmalar incelendiğinde bilinçli farkındalığın; psikolojik iyi oluş (Brown ve Ryan, 2003; Falkenström, 2010), romantik ilişkilerde memnuniyet (Barnes, Brown, Krusemark, Campbell ve Rogge, 2007), kayg1 ve agorafobi (Vujanovic, Zvolensky, Bernstein, Feldner ve McLeish, 2007), uyumlu psikolojik işlev gösterme (Lykins ve Baer, 2009), uykunun öz düzenlenmesi (Howell, Digdon ve Buro, 2010), kayg1 ve acıya duyarlılık (Zeidan, Gordon, Merchant ve Goolkasian, 2010), kaygi belirtileri (Vollestad, Svertsen ve Nielsen, 2011) ile ilişkili olduğu görülmektedir. Türkiye'de yapılan çalışmalar incelendiğinde ise bilinçli farkındalığın öz-anlayış (Özyeşil, 2011), ebeveynlik stili ve psikolojik sağlık (Kocaefe, 2013), tükenmişlik (Akyol, 2016), bağlanma biçimi ve psikolojik belirtiler (Albayrak, 2015), iş performansı ve iş doyumu (Çatalsakal, 2016) ile şizofreni hastalarının işlevsel iyileşme ve içgörü düzeyleri (Yılmaz, 2016) ile ilişkili olduğu bulunmuştur.

Stres ve bilinçli farkındalık arasındaki ilişkiyi inceleyen araştırmalara bakıldığında, betimsel ve deneysel olarak desenlenmiş birçok araştırmanın yapıldığı görülmektedir. Yapılan deneysel çalışmalarda bilinçli farkındalık temelli müdahalelerin hissedilen stres (Miller, Fletcher ve Kabat-Zinn, 1995), stres ve duygudurum bozukluğu belirtileri (Carlson, Ursuliak, Goodey, Angen ve Speca, 2001), iyi oluş, stres ve strese bağlı belirtiler (Carmody ve Baer, 2008), süreğen sağlık sorunları bulunan yetişkinlerin kaygı, depresyon ve psikolojik belirtileri (Bohlmeijer, Prenger, Taal ve Cuijpers, 2010), zihinsel iyi oluş, duygusal iyi oluş, öznel iyi oluş ve sosyal aktivite düzeyi (Colle, Vincent, Cha, Loehrer, Bauer ve Roedler, 2010), depresyon ve stres düzeyi (Demir, 2014) üzerinde etkili olduğu bulunmuştur. Yapılan betimsel çalışmalar açısından bakıldığında ise bilinçli farkındalığın kanser hastalarının stres ve duygudurum bozukluğu belirtileri (Carlson ve Brown, 2005), stresle başa çıkma tarzları (Palmer ve Rodger, 2009), travma sonras1 stres (Vujanovic, Youngwirth, Johnson ve Zvolensky, 2009), stres seviyesi ve stresle başa çıkma yolları (Weinstein, Brown ve Ryan, 2009), psikolojik iyi olma, stres, anksiyete ve depresyon (Cash ve Whittingham, 2010), stresle başa çıkma tarzları, depresyon, anksiyete ve stres belirtileri (Ülgev, 2014) ile anlamlı bir ilişki içinde olduğu görülmektedir.

Algılanan stres düzeyi ile çok yakın ilişkiye sahip bir diğer kavram da duygu düzenlemedir. Bu bağlamda Koole (2009) duygu düzenlemeyi, bireylerin duygu durumlarını yönetmek amaciyla olumlu ve olumsuz duygularını, ruh hallerini ve stres düzeylerini kapsayan bütün durumlarını düzenlemek için sergiledikleri aktif çaba olarak belirtmiştir. Bilinçli ve bilinçdışı bilişsel süreçleri kapsayan, davranışsal, sosyal ve biyolojik bir kavram olan (Ercan, 2015) duygu düzenlemeyi Thompson (1994) ise, bireyin belirli bir amaca ulaşabilmek adına, gözlem yapma ve değerlendirme süreçleri sonucu ortaya çıkan yoğun veya geçici duygusal tepkileri düzenleyebilme becerisi olarak tanımlamıştır.

Duygu düzenleme ile ilgili olarak Sosyal Bilgi Süreci Modeli (Dodge, 1991), Ortak Süreç Modeli (Gross, 1998), Bilişsel Duygu Düzenleme Modeli (Garnesfki, Kraaij ve Spinhoven, 2001) gibi birçok model ortaya atılmıştır. Alanyazına bakıldığında ise bilinçli farkındalık ile olumsuz duygulanım (Giluk, 2009), duygusal düzenleme (Roemer, Lee, Pedneault, Erisman, Orsillo ve Menin, 2009), kaygıya yönelik duygulanım düzeyi (Sears ve Kraus, 2009) ve duygu düzenleme güçlüğü (Gündüz, 2016) arasında anlamlı bir ilişki olduğu görülmektedir. Ekbland (2008) tarafından yapılan araştırmada ise bilinçli farkındalığa yönelik eğitim çalışmasının duyguları düzenleme ve dikkat üzerindeki etkisini incelenmiştir. Araştırmanın sonucunda bilinçli farkındalığa yönelik olarak uygulanan eğitim çalışmasının özellikle stres yaratan bir durumun sonrasında ortaya çıkan olumsuz duyguları azaltmada faydalı olduğu, psikolojik belirtiler ile dikkat üzerinde ise etkisinin olmadığı bulunmuştur.

Bilinçli farkındalık ve stres ile ilişkili olan bir diğer kavram da ruminasyondur. Ruminasyon; kişinin problemini çözüp, kendisine rahatsızlı ya da sıkıntı veren belirtileri değiştirmek için çaba harcaması yerine, pasif ve tekrarlayıcı bir biçimde içinde bulunduğu olumsuz duyguduruma, belirtilere ya da bu durumun sebep ve sonuçlarına odaklanmasidır (Nolen-Hoeksema, Wisco ve Lyubomirsky, 2008). Calhoun, Cann, Tedeschi ve McMillan 
(2000), ruminasyonu travmatik yaşantılar perspektifinden ele alarak "yaşanan olayla ilişkili olarak ortaya çıkan; tekrarlayıcı, problem çözme, anımsama ve beklentiyi içeren düşünme şekli" olarak tanımlamışlardır. Daha geniş bir perspektiften bakıldığında ise ruminasyonun sadece geçmiş yaşantılara yönelik olarak ortaya çıkmadığ görülmektedir. Ruminatif düşünceler; bireyin kendisi, başkaları, geçmiş, şu an, gelecek, tamamlanmış, tamamlanmamış ya da daha farklı durumlara yönelik olarak da ortaya çıkabilmektedir. (Martin ve Tesser, 1996; Papageorgiou ve Wells, 2004).

Ruminasyon; olumsuz duyguların nasıl geliştiği ve 1srarlı bir biçimde devam ettiğinin aydınlatılması açısından sıklıkla incelenen önemli bir kavramdır (Smith ve Alloy, 2009). Özellikle son yirmi yıldır daha yoğun bir biçimde araştırılmaya başlanan bu kavramın farklı kuram ve modeller çerçevesinde açıklanmaya çalışıldığı görülmektedir (Thomsen, 2006). Depresyon ile ilişkilendirilen ruminasyona yönelik olarak Nolen-Hoeksema'nın ortaya koyduğu Tepki Biçimleri Kuramı (Response Styles Theory), ruminasyon ile ilgili alan yazında en sık vurgu yapılan kuram olarak karşımıza çıkmaktadır. Alloy ve diğerleri (2000) ise, NolenHoeksema'nın Tepki Stilleri Kuramı ile Beck'in Bilişsel Kuramı'nı temel alarak "strese tepki olarak ruminasyon (stress reactive rumination)" kavramını ortaya atmışlardır. Bu modele göre ruminasyon; "stresli yaşam olayından sonra kişinin olumsuz çıkarımlarda bulunması ve bu olumsuz düşünce ve bilişleri sıklıkla zihne getirmesi" olarak tanımlanmaktadır (Alloy ve diğerleri, 2000). Bir başka deyişle tepki biçimleri kuramında ruminasyon, depresif duygu duruma bir tepki olarak ortaya çıkarken; strese tepki olarak ruminasyon modelinde ruminasyonun depresyonun başlangıcından önce ortaya çıktığı savunulmaktadır (Eker, 2016).

Ruminasyon ile ilgili alanyazın incelendiğinde ruminasyonun daha çok depresyon ile ilişkisinin araştırıldığı görülmektedir. Deneysel çalışmalar açısından ele alındığında; bilinçli farkındalık temelli uygulamaların ruminasyon ve depresyon üzerinde etkili olduğu ortaya çıkmıştır (Burg ve Michalak, 2011; Deyo, Wilson, Ong ve Kopman, 2009; Michalak, Hölz ve Teismann, 2011). Bilinçli farkındalık ve stres temelinde bakıldığında ise bilinçli farkındalık temelli stres azaltma programlarının ruminatif düşünmeyi azaltmada etkili olduğu görülmektedir (Jain, Shapiro, Swanick, Roesch, Mills, Bell ve Schwartz, 2007; Ramel, Goldin, Carmona ve McQuaid, 2004; Raes ve Williams, 2010). Yapılan diğer araştırmalara bakıldığında bilinçli farkındalık temelli uygulamaların; davranışsal, bilişsel, emosyonel saldırganlık ve ruminasyon (Borders, Earleywine ve Jajodia, 2010) ile kanser hastalarının bilinçli dikkat ve ruminatif düşünme düzeyleri (Campbell, Labelle, Bacon, Faris ve Carlson, 2012) üzerinde etkili olduğu bulunmuştur.

Bilinçli farkındalık ile stres arasındaki ilişkiyi ortaya koyan birçok araştırma bulunmasına karşın bu iki değişken arasındaki ilişkinin altında yatan mekanizmanın araştırılmasının önemli olduğu düşünülmektedir. Bu araştırmada bilinçli farkındalık ile stres arasındaki ilişkide ruminasyon ve olumsuz duygu düzenlemenin aracı etkisi incelenmiştir. Farklı araştırmalarda ruminasyon ve olumsuz duygu düzenlemenin stres ve bilinçli farkındalık üzerindeki etkileri ayrı ayrı incelense de bu iki değişkenin aracılık rolünün ortaya konması konu ile ilgili alanyazına önemli katkılarda bulunacaktır. Özetle bu araştırmanın amacı; üniversite öğrencilerinin bilinçli farkındalık ve algıladıkları stres arasındaki ilişkide ruminasyon ve olumsuz duygu düzenlemenin aracı rolünün incelenmesidir. Bu amaçla ilgili alanyazın ışığında aşağıda belirtilen hipotezler incelenmektedir:

1. Bilinçli farkındalık, algılanan stresi anlamlı bir biçimde yordamaktadır.

2. Ruminasyonun bilinçli farkındalık ve algılanan stres arasında aracı rolü bulunmaktadır.

3. Olumsuz duygu düzenlemenin bilinçli farkındalık ve algılanan stres arasında aracı rolü bulunmaktadır.

\section{Yöntem}

\section{Çalıșma grubu}

Araştırma 2016-2017 akademik yılında Çukurova Üniversitesi’nde öğrenim gören 425'i kadın (\%57) ve 320'si erkek (\%43) olmak üzere toplam 745 üniversite öğrencisi ile 
gerçekleştirilmiştir. Araştırmaya katılan üniversite öğrencilerinin 244'ü Eğitim (\%32.8), 109'u İktisadi ve İdari Bilimler (\%14.6), 104'ü Fen-Edebiyat (\%14), 102'si Mühendislik (\%13.7), 68'i İlahiyat (\%9.1), 53'ü Ziraat (\%7.1), 34'ü Veterinerlik Fakülteleri (\%4.6) ve 31'i Beden Eğitimi ve Sağlık Yüksek Okulu'na (\%4.2) devam etmektedirler. Öğrenciler 17-39 yaş aralığında olup, yaş ortalamaları 21.64'dür ( $\mathrm{Ss}=2.77)$.

\section{Veri toplama araçları}

Bilinçli Farkındalık Ölçeği (BİFÖ): Brown ve Ryan (2003) tarafından geliştirilen BİFÖ, bireylerin bilinçlilik durumlarının sıklığındaki bireysel farklılıkları ve günlük yaşamdaki anlık deneyimlere odaklanma ve farkında olma eğilimini ölçmektedir. BİFÖ 15 maddeden oluşmakta olup, 6'lı Likert tipinde bir ölçektir. Ölçek "Hemen hemen her zaman"dan, "Hemen hemen hiç"e kadar derecelendirilerek cevaplandırılmaktadır. Ölçekten elde edilen yüksek puanlar bilinçli farkındalığın yüksekliğine işaret etmektedir. Ölçek Özyeşil, Arslan, Kesici ve Deniz (2011) tarafından Türkçeye uyarlanmıştır. Ölçeğin faktör yapılarını belirleyebilmek için açımlayıcı ve doğrulayıcı faktör analizi uygulanmış ve ölçeğin orijinal formunda olduğu gibi tek boyutlu bir yapı gösterdiği görülmüştür (RMSEA $=.06$, standardize edilmiş $\mathrm{RMS}=.06, \mathrm{GFI}=.93$ ve AGFI=.91) Yapılan madde toplam korelasyonunda ölçeğin bütün maddeleri için .40 'ın üzerinde ilişki ortaya çıkmıştır. Her bir madde için madde faktör yükleri ise .48 ile .81 arasında değişmektedir. Ölçeğin Cronbach Alpha iç tutarlılık katsayısı .80, test-tekrar test korelasyonu ise .86 olarak saptanmıştır. BİFÖ’nün ölçüt-bağıntılı geçerliği için yapılan korelasyon analizleri sonucunda; BİFÖ'den alınan puanlar ile Depresyon Anksiyete ve Stres Ölçeği'nin depresyon, anksiyete ve stres alt boyutları ile negatif yönde, anlamlı ve yüksek düzeyde; Pozitif ve Negatif Duygu Ölçeği'nin pozitif duygu alt boyutu ile pozitif yönde, negatif duygu alt boyutu ile negatif yönde, anlamlı ve yüksek düzeyde; Öz-anlayış Ölçeği puanları arasında ise pozitif yönde; ilişkiler saptanmıştır.

Algılanan Stres Ölçeği (ASÖ): Cohen, Kamarck ve Mermelstein (1983) tarafindan geliştirilmiş olan ölçek, Birleşik Devletler, Kanada ve Avrupa'da farklı gruplar üzerinde yürütülen çalışmalarda oldukça yaygın bir biçimde kullanılan bir ölçme aracıdır. ASÖ, yaşanan stresin düzeyini, yanıtlayıcının yaşamını ne ölçüde yordanamaz, kontrol edilemez ve aşırı yüklü değerlendirdiğine bağl1 olarak ölçmek üzere geliştirilmiş, 14 maddeden oluşan bir kendini değerlendirme ölçeğidir. Ölçekteki maddeler 0 (hiç) ile 5 (çok sık) arasında 5'li Likert derecelendirmeye göre puanlanmaktadır. Ölçekten alınan yüksek puan algılanan stres düzeyinin yüksekliğine işaret etmektedir. ASÖ'nün Türkçe'ye uyarlanması Yerlikaya ve İnanç (2007) tarafından gerçekleştirilmiştir. Ölçeğin güvenirliğini sınamak üzere hesaplanan iç tutarlık alfa katsayısının .84 olduğu görülmüştür. ASÖ puanları ile Beck Depresyon Ölçeği ve Durumluk Sürekli Kaygı Envanteri-I ve II puanları arasında ise sirasıyla $.65, .56, .66$ düzeyinde pozitif yönde korelasyonlar olduğu saptanmıştır. Sonuçlar ASÖ Türkçe formunun yeterli iç tutarlılığa ve ölçüt geçerliğine sahip olduğunu destekler niteliktedir.

Ruminatif Düşünme Biçimi Ölçeği (RDBÖ): Ruminatif Düşünme Biçimi Ölçeği, Brinker ve Dozois (2009) tarafından geliştirilmiş, yalnızca belirli psikopatolojik durumlara özgü olarak ortaya çıkan ruminasyonu değil, bütün ruminatif düşünme biçimlerini değerlendiren, ruminasyonu psikopatolojilerden bağımsız bir bilişsel süreç olarak ele alan bir ölçme aracıdır. Ölçekteki maddeler 1 (hiç) ile 7 (çok iyi) arasında 7'li Likert derecelendirmeye göre puanlanmaktadır. RDBÖ, 20 maddeden oluşmakta olup, tek bir toplam puan veren bir ölçme aracıdır. Alınan yüksek puan ruminatif düşünmenin fazla olduğunu göstermektedir. Ölçeğin Türkçe formunun geçerlik ve güvenirlik çalışması Karatepe, Yavuz ve Türkcan (2013) tarafından yapılmıştır. Ölçeğin Türkçe formunun tüm test için Cronbach alfa iç tutarlık katsayısı .91'dir. Faktör analizi sonucunda ölçeğin orijinal formundaki gibi, toplam varyansın \%63.43'ünü açıklayan tek faktörlü bir yapıya sahip olduğu belirlenmiştir. Ölçeğin test-tekrar test korelasyon katsayısı .84 olarak bulunmuştur. RDBÖ'nün yakınsak geçerliği için LDŞÖ 
(Leahy Duygusal Şema Ölçeği)-ruminasyon alt ölçeği ve Üstbiliş-30 ölçekleri ile arasındaki korelasyonlara bakılmış ve anlamlı ilişkiler elde edilmiştir. Ayırt edici geçerliliğin araştırılması için RDBÖ'nün puanları ile LDŞÖ-hislerin kabullenilmesi ve anlaşılırlık alt ölçekleri puanları arasındaki ilişkiler incelenmiş ve negatif yönde anlamlı ilişkiler elde edilmiştir.

Olumsuz Duygudurum Düzenlemesi Ölçeği (ODDÖ): Catanzaro ve Mearns (1990) tarafından geliştirilen ölçek Bahadır (2006) tarafından Türkçeye uyarlanmıştır. Ölçek 30 maddeden oluşmakta olup, 5'li Likert türündedir. Ölçeğin toplamından alınabilecek en düşük puan 30 en yüksek puan 150 'dir. Ölçekten alınan yüksek puanlar bireylerin olumsuz duygudurum ile daha iyi baş etme beklentilerine sahip olduklarını göstermektedir. ODDÖ olumsuz duygudan uzaklaşma, aktif çaba, yüzleşme ve sosyal destek olmak üzere dört alt ölçekten oluşmakta olup, iç tutarlık katsayıları .58 ve .82 arasında değişmektedir. Ölçeğin toplamının iç tutarlık katsayıs1.88, test- tekrar test güvenirliği .85 olarak bulunmuştur. Faktör analizi sonucunda elde edilen alt boyutların korelasyonları .61-.83 arasında değiş̧mektedir. Doğrulayıcı faktör analizine göre elde edilen 4 bileşenin faktör yapısının yeterli geçerliliğe sahip olduğu belirlenmiştir. ODDÖ'nün ölçüt bağıntılı geçerliği hakkında bilgi sahibi olmak amacıyla ölçeğin ve alt boyutlarının hem Beck Depresyon Ölçeği hem de Rotter'ın İç-Dış Kontrol Odağı Ölçeği ile ilişkisine bakılmıştır. Beklendiği gibi hem tüm ölçek hem de alt boyutlarla hem Beck Depresyon Ölçeği hem de Kontrol Odağı Ölçeği puanları arasında olumsuz anlamlı ilişkiler belirlenmiştir. $\mathrm{Bu}$ araştırmada ölçeğin toplam puanı kullanılmıştır.

\section{İşlem}

Öncelikle araştırmacılar tarafından araştırma grubunda yer alan katılımcılara çalışmanın amacı, süresi ve verilerin gizliliği ile ilgili bilgi verilmiştir. Uygulamalar sınıf ortamında gerçekleştirilmiştir. Veri toplama araçları araştırmaya gönüllü olarak katılmak isteyen öğrencilere uygulanmıştır. Katılımcılar ölçekleri yaklaşık 20 dakikada yanıtlamışlardır.

\section{Verilerin analizi}

Araştırmada üniversite öğrencilerinin bilinçli farkındalıkları ile algıladıkları stres arasındaki iliş̧kide ruminasyon ve olumsuz duygudurum düzenlemenin aracılık rolü incelenmiştir. Öncelikle bütün değişkenlere ilişkin betimsel istatistikler hesaplanmış, değişkenler arası ilişkiler Pearson Çarpım Momentler Korelasyon analizi kullanılarak belirlenmiştir. Son olarak aracılık analizleri Preacher ve Hayes'in (2008) önerileri doğrultusunda gerçekleştirilmiştir. Dolaylı etkilerin anlamlılığını incelemek için hem Sobel Z, hem de Preacher ve Hayes'in (2008) bootstrapping prosedürü kullanılmıştır. $\mathrm{Bu}$ araştırmada 10000 bootstrap yapılarak bootstrap katsayısı ve güven aralıkları belirlenmiştir. Belirtilen analizler IBM SPSS Statistics 21.00 kullanılarak gerçekleştirilmiştir.

\section{Bulgular}

\section{Betimsel istatistikler ve korelasyonlar}

Araştırmada değişkenler arasındaki ilişkileri incelemek üzere Pearson Çarpım Momentler Korelasyon analizi yapılmıştır. Ayrıca değişkenlere ait betimsel istatistikler de hesaplanmıştır. Analiz sonuçları Tablo 1'de yer almaktadır.

Tablo 1'de görüldüğü gibi, çarpıklık ve basıklık değerleri açısından araştırmada ele alınan tüm değişkenler normallik sayıltılarını karşılamaktadır. Bilinçli farkındalık ile stres $(r=-$ $.43, \mathrm{p}<.001)$ ve ruminasyon $(\mathrm{r}=-.38, \mathrm{p}<.001)$ arasinda negatif yönde anlaml, olumsuz duygudurum düzenleme ile ise $(\mathrm{r}=.41, \mathrm{p}<.001)$ pozitif yönde anlamlı ilişkiler bulunmaktadır. Ayrica algılanan stres ile ruminasyon arasında pozitif yönde $(\mathrm{r}=.43, \mathrm{p}<.001)$, olumsuz duygudurum düzenleme ile ise negatif yönde $(\mathrm{r}=-.52, \mathrm{p}<.001)$ anlamlı ilişkiler belirlenmiştir. 
Tablo 1.

Bilinçli Farkındalık, Stres, Ruminasyon ve Olumsuz Duygudurum Düzenleme Arasındaki İlişkiler ve Betimsel İstatistikler

\begin{tabular}{lcccccccc}
\hline & \multicolumn{3}{c}{ Korelasyonlar } & \multicolumn{2}{c}{ Betimsel İstatistikler } \\
\hline & 1 & 2 & 3 & 4 & $\mathrm{X}(\mathrm{Ss})$ & Çarpıklı & Basılklk & Alfa \\
\hline 1.Bilinçli farkındalık & - & & & & $58.30(11.38)$ & -.40 & .80 & .82 \\
2. Stres & $-.43^{*}$ & - & & & $21.81(6.23)$ & .07 & .26 & .85 \\
3. Ruminasyon & $-38^{*}$ & $.43^{*}$ & - & & $93.17(23.18)$ & -.21 & -.24 & .93 \\
$\begin{array}{l}\text { 4. Olumsuz duygudurum } \\
\text { düzenleme }\end{array}$ & $.41^{*}$ & $-.52^{*}$ & $-.47^{*}$ & - & $98.58(15.76)$ & -.35 & 1.29 & .89 \\
\hline
\end{tabular}

$* \mathrm{p}<.001$

\section{Aracılık analizleri}

Bilinçli farkındalık, stres ve aracı değişken olarak ele alınan ruminasyon ve olumsuz duygudurum düzenleme arasındaki ilișkiler regresyon analizi kullanılarak incelenmiștir. Ayrıca dolaylı etkilerin değerlendirilmesinde Sobel $Z$ ve bootstrapping kullanılmıştır. Şekil 1'de bilinçli farkındalık ve stres arasındaki ilişkide ruminasyon ve olumsuz duygudurum düzenlemenin aracı rolünü gösterir modeller yer almaktadır.

\section{Bilinçli farkındalık ve stres arasındaki ilişkide ruminasyonun aracı rolü}

Beklenildiği gibi bilinçli farkındalık ruminasyonu anlamlı düzeyde negatif yordamaktadır $\left(\mathrm{B}_{\mathrm{Sh}}=\right.$ $-.77 .07, \mathrm{t}=-11.10, \mathrm{p}<.001)$. Ruminasyon stresi pozitif yönde anlamlı yordamaktadır $\left(\mathrm{B}_{\mathrm{Sh}}=.08 .01\right.$, $\mathrm{t}=9.05, \mathrm{p}<.001)$. Bilinçli farkındalığın algılanan stres üzerindeki doğrudan etkisi $\mathrm{B}_{\mathrm{Sh}}=-.17 .02, \mathrm{t}=$ $-9.13, p<.001$ olarak belirlenmiştir. Bilinçli farkındalığın ruminasyon aracılığıyla dolaylı etkisi ise $a b=-.06$ 'dır. Aracı değişken eşitliğe girildikten sonra bilinçli farkındalığın stres üzerindeki etkisi düşmüştür (-.23'den -.17'ye). Baron ve Kenny'e (1986) göre bu durum k1smi aracillğ göstermektedir. Dolaylı etkinin normalliği varsayımına dayanan Sobel Z testi sonuçlarına göre ruminasyon bilinçli farkındalık ve stres arasında aracı role sahiptir $(Z=-6.99, p<.001)$. Bootstrapping sonuçları da aynı sonuca işaret etmektedir (Bootstrap katsayısı $=-.06, \mathrm{Sh}=.01$, $\% 95 \mathrm{GA}=-.09,-04)$. Hayes (2013) dolaylı etkinin anlamlı olduğuna karar verebilmek için güven aralığının alt ve üst sınırının sıfırı kapsamaması gerektiğini belirtmektedir.

Bilinçli farkındalık ve stres arasındaki ilişkide olumsuz duygudurum düzenlemenin aracı rolü Regresyon analizi sonuçlarına göre bilinçli farkındalık olumsuz duygudurumu düzenlemeyi anlamlı düzeyde pozitif yordamaktadır $\left(\mathrm{B}_{\mathrm{Sh}}=.56 .05, \mathrm{t}=12.09, \mathrm{p}<.001\right)$. Olumsuz duygudurum düzenleme ise algılanan stresi negatif yönde anlamlı yordamaktadır $\left(B_{S h}=-.16 .01, t=-12.51\right.$, $\mathrm{p}<.001$ ). Bilinçli farkındalığın algılanan stres üzerindeki doğrudan etkisi $\mathrm{B}_{\mathrm{Sh}}=-.14 .02, \mathrm{t}=-7.85$, $\mathrm{p}<.001$ olarak belirlenmiştir. Bilinçli farkındalığın olumsuz duygudurumu düzenleme aracıllğıyla dolaylı etkisi ise $a b=-.09$ 'dur. Aracı değişken eşitliğe girildikten sonra bilinçli farkındalığın stres üzerindeki etkisi düşmüştür (-.23'den -.14'e). Baron ve Kenny'e (1986) göre bu durum kısmi aracılığ göstermektedir. Dolaylı etkinin normalliği varsayımına dayanan Sobel $\mathrm{Z}$ testi sonuçlarına göre olumsuz duygudurumu düzenleme bilinçli farkındalık ve stres arasında aracı role sahiptir $(Z=-8.68, p<.001)$. Bootstrapping sonuçları da aynı sonuca işaret etmektedir (Bootstrap katsayıs1 $=-.09, \mathrm{Sh}=.01, \% 95 \mathrm{GA}=-.12,-07$ ). 

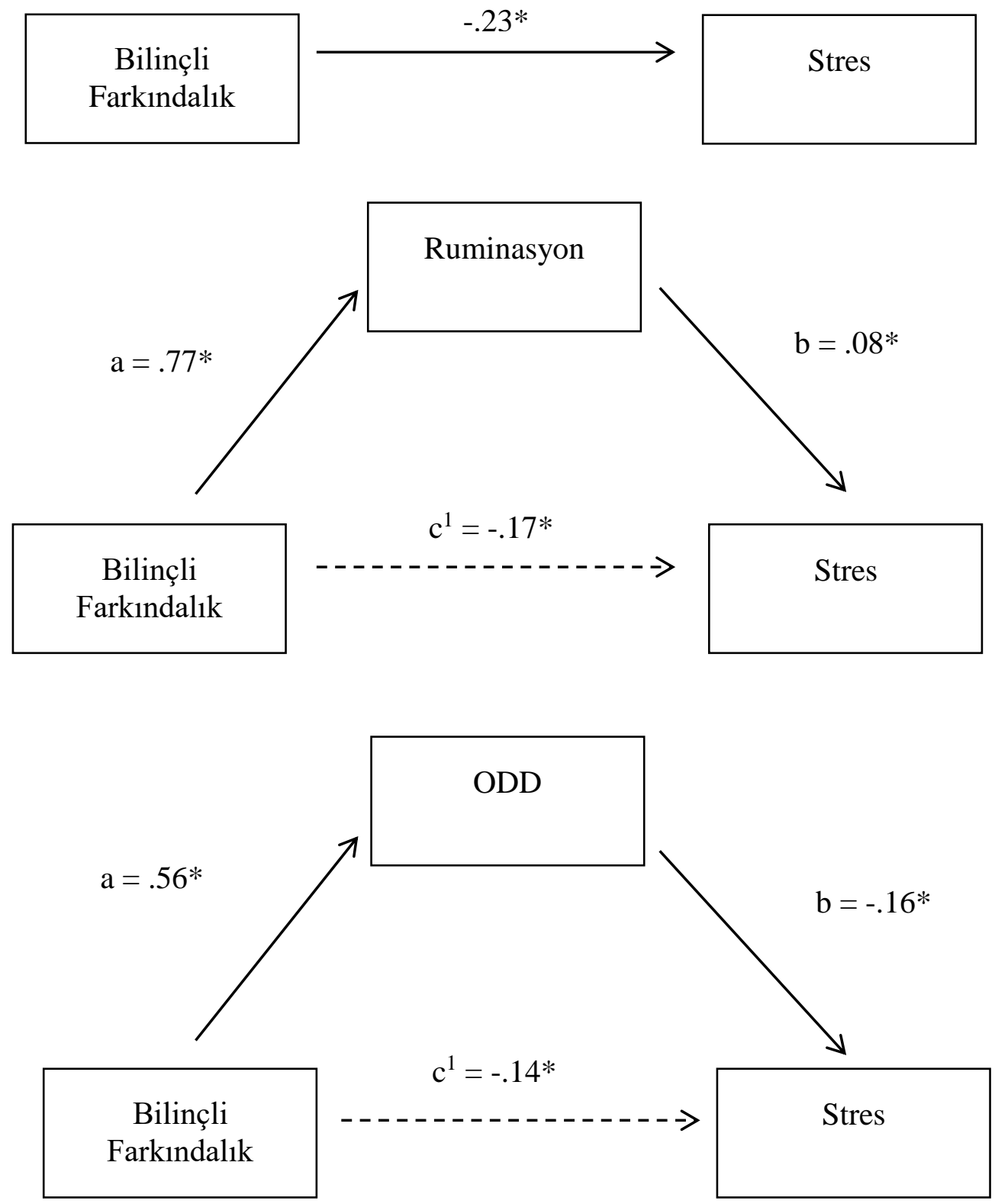

$* \mathrm{p}<.001$

Şekil 1. Ruminasyon ve ODD’nin bilinçli farkındalık ve stres arasındaki ilişkideki aracı rolü

\section{Tartışma / Sonuç ve Öneriler}

$\mathrm{Bu}$ çalışmada bilinçli farkındalık ve stres arasındaki ilişkide ruminasyon ve olumsuz duygudurum düzenlemenin araci etkisi incelenmiş, hem ruminasyon hem de olumsuz duygudurum düzenlemenin bilinçli farkındalık ve stres arasında kısmi aracı rolü olduğu saptanmıştır. Araştırmada öncelikle değişkenler arası ilişkiler incelenmiştir. Çalışmanın korelasyonel bulguları algılanan stresin bilinçli farkındalık ve olumsuz duygudurum düzenleme ile negatif, ruminasyon ile ise pozitif ilişkili olduğunu göstermektedir.

Bu sonuçlar stres ve bilinçli farkındalık (Cash ve Whittingham, 2010; De Lissnyder ve diğerleri, 2012; Ülev, 2014; Weinstein, Brown ve Ryan, 2009), ruminasyon (Alloy ve diğerleri, 2000; Mezo ve Baker, 2012; Roger ve Hudson, 1995; Smith ve Alloy, 2009;) ve olumsuz 
duygudurum düzenleme (Ekbland, 2008; Koole, 2009; Wang ve Saudino, 2011) arasındaki ilişkilere yönelik yapılmış araştırma sonuçlarıyla tutarlılık göstermektedir.

$\mathrm{Bu}$ çalışmada bilinçli farkındalık ve stres arasındaki ilişkide ruminasyonun kısmi aracılık rolü oynadığı belirlenmiştir. Bir başka deyişle, öğrencilerin bilinçli farkındalıklarının artması onların ruminasyon düzeylerini azaltmakta ve bu düşüşle birlikte algıladıkları stres azalmaktadir.

Bilinçli farkındalık ile ruminasyon arasındaki ilişkiye değinen Ögel (2012), ruminasyonun artması ile birlikte ruminatif düşünceye ait içeriğin bireyin gerçekliği haline gelmeye başlayacağını ve bu durumun bir sonucu olarak da kişinin çevresinde olanlara yönelik farkındalığının azalacağını belirtmiştir. Kuramsal olarak bakıldığında da ruminasyonun zihinsel süreçlere yönelik yoğun uğraş içerisinde olmayı tanımladığı (Nolen-Hoeksema, Wisco ve Lyubomirsky, 2008), bilinçli farkındalığın ise ruminasyondan farklı olarak düşünceden bağımsız bir biçimde yaşanan an ile ilgili bedensel ve çevresel duyumları kapsadığ görülmektedir (Kabat-Zinn, 2003). Raes ve Williams da (2010) bilinçli farkındalık ile ruminatif düşünme biçimi arasında negatif yönlü anlamlı bir ilişki bulunduğunu belirtmiştir. Bu bulguyu destekleyen deneysel çalışmalar da bulunmaktadır. Bilinçli farkındalığı artırmaya yönelik olarak gerçekleştirilen çalışmaların ruminasyon düzeyini azaltmada etkili olduğu yapılan çalışmalarda ortaya çıkmıştır (Campbell, Labelle, Bacon, Faris ve Carlson, 2012; Deyo, Wilson, Ong ve Koopman, 2009; Michalak, Hölz ve Teismann, 2011; Ramel, Goldin, Carmona ve McQuaid, 2004). Özet olarak belirtmek gerekirse, araştırma sonucunda ortaya çıkan "bilinçli farkındalığın artmasının ruminasyon düzeyinde azalmaya neden olduğu" sonucu ilgili alanyazın tarafından da desteklenmektedir.

Ruminasyon ile stres arasındaki ilişki açısından bakıldığında ise; alanyazında ruminasyonun işlevi hakkında farklı görüşlerin olduğu dikkati çekmektedir. Bazı araştırmacılar ruminasyonun yapıcı etkilerine vurgu yaparak, ruminatif düşünme biçiminin özellikle travmatik olayların atlatılmasına katkı sağlayabileceğini belirtmişlerdir (Watkins, 2008). Buna benzer görüşlere karşın yapılan birçok araştırma ruminasyonun daha çok olumsuz duygu ve psikolojik sorunlarla bağlantılı olduğunu ortaya koymuştur (Thomsen, 2006). Özellikle uzun süre geçmesine rağmen ruminatif düşüncelerin intrusif (zorlayıcı ya da girici) bir şekilde devam etmesinin psikolojik zorlanmalara yol açtığı düşünülmektedir (Calhoun, Cann, Tedeschi ve Mcmillan, 2000; Taku, Cann, Tedeschi ve Calhoun, 2009). Depresyon, kayg1 ve travma sonras1 stres bozukluğu gibi sorunların, sıklıkla ruminasyon ile ilişkilendirildiği görülmektedir (Wilkinson, Croudace ve Goodyer, 2013). Alloy ve diğerleri de (2000) stres ve ruminasyon arasındaki ilişkiye dikkati çekerek ruminasyonu, çeşitli yaşam olaylarından sonra ortaya çıkan düşünce ve bilişlerin zihne getirilmesi olarak ele almışlardır. Araştırma sonuçları ile ortaya çıkan, ruminasyon ve stres arasındaki bu ilişkinin alanyazında da çeşitli araştırmalar ile desteklendiği görülmektedir (De Lissnyder ve diğerleri, 2012; Mezo ve Baker, 2012; Roger ve Hudson, 1995; Smith ve Alloy, 2009). Sonuç olarak, "ruminasyon düzeyindeki azalmanın algılanan stres seviyesinde azalmaya neden olduğu" sonucunun ilgili alanyazın ile paralellik gösterdiği söylenebilir.

Bilinçli farkındalık ile stres arasındaki ilişkide ruminasyonun aracı rolüne ilişkin ortaya çıkan sonuç, Ciesla ve diğerleri (2012) tarafından yapılan araştırma sonuçları ile de örtüşmektedir. Lise öğrencileri ile yaptıkları çalışmada araştırmacılar bilinçli farkındalık ile stres arasındaki ilişkide günlük ruminasyonun aracılık rolü olduğunu bulmuşlardır. Ortaya çıkan bu sonuç bilinçli farkındalık ile algılanan stres arasındaki ilişkide ruminasyonun aracı rolünün öğrencilerin eğitim kademelerinden bağımsız olarak geçerli olduğunu düşündürmektedir.

Araştırmada olumsuz duygudurum düzenlemenin bilinçli farkındalık ve stres arasındaki ilişkide kısmi aracı role sahip olduğu belirlenmiştir. Bir başka deyişle öğrencilerin bilinçli farkındalıklarının artması onların olumsuz duygudurum düzenleme becerilerini yükseltebilmekte ve bu yükselişle birlikte algıladıkları stres azalabilmektedir.

Bilinçli farkındalık ile olumsuz duygudurum düzenleme arasındaki bu sonuç alanyazında yer alan çeşitli araştırmalarla örtüşmektedir. Giluk (2009) bilinçli farkındalık ile olumsuz duygulanım arasında negatif yönde anlamlı bir ilişki olduğunu; Gündüz (2016) ise 
bilinçli farkındalık ile duygu düzenleme güçlüğü arasında negatif yönlü ilişki bulunduğunu belirtmiştir. Sears ve Kraus (2009) ise bilinçli farkındalık temelli meditasyon programı katılımcılarının kaygıya yönelik duygulanım düzeylerinin anlamlı derecede azaldığını belirtmiştir.

Olumsuz duygudurumu düzenleme ile stres arasındaki ilişki açısından bakıldığında ise araştırma sonuçlarını destekleyen çeşitli araştırmalar olduğu görülmektedir. Koole (2009) duygu düzenlemeyi bireyin stres düzeyini de içine alan bir kavram olarak ele almış, Wang ve Saudino (2011) ise duygu düzenleme, olumsuz duygularla baş etme ve stres arasında çok yakın bir ilişki olduğunu belirtmiştir. Ekbland'da (2008) bilinçli farkındalık temelli eğitim çalışmasının stres sonrasında ortaya çıkan olumsuz duyguları azaltmada etkili olduğunu belirtmiştir.

Sonuç olarak üniversite öğrencilerinde bilinçli farkındalığın gerek doğrudan gerekse de ruminasyon ve olumsuz duygudurum düzenleme aracılığıyla algılanan stresi anlamlı şekilde etkilediği söylenilebilir. Ancak hem ruminasyon hem de olumsuz duygudurum düzenlemenin aracılık etkisinin kısmi bir etki olduğu dikkate alınmalıdır. Bu durumda aracı rol oynayabilecek diğer değişkenlerin (otomatik düşünce, iyimserlik, otantik olma, psikolojik sağlamlık, duygusal zekâ, kontrol odağı vb.) başka araştırmalarda ele alınması bilinçli farkındalık ve stres arasındaki ilişkinin doğasını anlamada önemli katkılar sunacaktır.

$\mathrm{Bu}$ araştırmanın sınırlılıklarından biri yalnızca üniversite öğrencileri üzerinde gerçekleştirilmesidir. Bu konuda gelecekte yapılacak araştırmalar çocuk, ergen, yetişkin ve yaşlılar gibi farklı örneklem gruplarında gerçekleştirilebilir. Ayrıca bu araştırmada örnekleme dâhil olan üniversite öğrencilerinin psikopatolojik durumları dikkate alınmamıştır. Bu nedenle ileride gerçekleştirilecek çalışmalarda psikopatoloji sergileyen ve sergilemeyen öğrenciler ayrı ayrı ele alınarak sonuçlar arasında bir farklılaşma olup olmadığı da değerlendirilebilir. Ayrıca farklı değişkenlerin kullanılmasının veya farklı istatistiksel yöntemler ile analizlerin yapılmasının farklı bulgu ve sonuçlara ulaşmak adına yararlı olabileceği düşünülmektedir.

Bilinçli farkındalığın gerek doğrudan gerekse de ruminasyon ve olumsuz duygudurum düzenleme aracılığıyla algılanan stresi azaltma üzerinde etkili olduğu göz önüne alındığında üniversite öğrencilerine yönelik bilinçli farkındalığı geliştirme eğitim programlarının hazırlanmas1, bu programların ruminasyonu, olumsuz duygudurumu ve algilanan stresi nasil etkilediğine ilişkin deneysel çalışmaların yapılması önerilmektedir. Alanyazına bakıldığında Türkiye'de gençlerde bilinçli farkındalığ 1 geliştirmeye yönelik yapılmış deneysel çalışmaların sınırlı olduğu, bu çalışmalar içerik açısından incelendiğinde ise ruminasyon ve duygu düzenlemeyi içermediği görülmektedir. Bu nedenle ruminasyon ve olumsuz duygudurumu düzenlemeye yönelik etkinliklerin yer verildiği bilinçli farkındalık temelli deneysel çalışmaların stres üzerindeki etkisinin incelenmesinin önemli olduğu değerlendirilmektedir.

\section{Kaynaklar}

Akyol, E. Y. (2016). Üniversite son sinıf ögrencilerinin farkındalıklarının yordayıcısı olarak tükenmişlik (Yayımlanmamış yüksek lisans tezi). Orta Doğu Teknik Üniversitesi, Ankara.

Albayrak, B. (2015). Üniversite öğrencilerinin bağlanma biçimleri, bilinçli farkındalık düzeyleri ve psikolojik belirtileri arasındaki iliş̧kiler (Yayımlanmamış yüksek lisans tezi). Hasan Kalyoncu Üniversitesi, İstanbul.

Alloy, L. B., Abramson, L. Y., Hogan, M. E, Whitehouse, W. G., Rose, D. T., Robinson, M. S. ve Kim, R. S. (2000). The temple-wisconsin cognitive vulnerability to depression project: lifetime history of axis i psychopathology in individuals at high and low cognitive risk for depression. Journal of Abnormal Psychology, 109(3), 403-418.

Bahadır, Ş. (2006). Romantik ilişsilerde bağlanma stilleri, çatışma çözme stratejileri ve olumsuz duygudurumunu düzenleme arasındaki ilişki (Yayımlanmamış doktora tezi). Ankara Üniversitesi, Ankara.

Barnes, S., Brown, K. W., Krusemark, E., Campbell, W. K. ve Rogge, R. D. (2007). The role of mindfulness in romantic relationship satisfaction and responses to relationship stress. Journal of Marital and Family Therapy, 33(4), 482-500. 
Baron, R. M. ve Kenny, D. A. (1986). The moderator-mediator variable distinction in social psychological research: Conceptual, strategic, and statistical considerations. Journal of Personality and Social Psychology, 51(6), 1173-1182.

Bishop, S. R., Lau, M., Shapiro, S., Carlson, L., Anderson, N. D., Carmody, J., Segal, Z. V., Abbey, S., Speca, M., Velting, D. ve Devins, G. (2004). Mindfulness: A proposed operational definition. Clinical Psychology: Science and Practice, 11, 230-241.

Bohlmeijer, E., Prenger, R., Taal, E. ve Cuijpers, P. (2010). The effects of mindfulness-based stress reduction therapy on mental health of adults with a chronic medical disease: A meta-analysis. Journal of Psychosomatic Research, 68(6), 539-544.

Borders, A., E, Earleywine, M. ve Jajodia, A. (2010). Could mindfulness decrease anger, hostility, and aggression by decreasing rumination? Aggressive Behavior, 36(1), 28-44.

Budak, S. (2001). Psikoloji sözlüğ̈̈. Ankara: Bilim ve Sanat Yayınları.

Burg, J. M. ve Michalak, J. (2011). The healthy quality of mindful breathing: associations with rumination and depression. Cognitive Therapy and Research, 35(2), 179-185.

Brinker, J. K. ve Dozois, D. J. A. (2009). Ruminative thought style and depressed mood. Journal of Clinical Psychology, 65(1), 1-19.

Brown, K. W. ve Ryan, R. M. (2003). The benefits of being present: mindfulness and its role in psychological well-being. Journal of Personality and Social Psychology, 84(4), 822848.

Calhoun, L. G., Cann, A., Tedeschi, R. G. ve McMillan, J. (2000). A correlational test of the relationship between postraumatic growth, religion, and cognitive processing. Journal of Traumatic Stress, 13, 521-527.

Campbell, T. S., Labelle, L. E., Bacon, S. L., Faris, P. ve Carlson, L. E. (2012). Impact of mindfulness-based stress reduction (MBSR) on attention, rumination and resting blood pressure in women with cancer: A waitlist-controlled study. Journal of Behavioral Medicine, 35(3), 262-271.

Carlson, L. E. ve Brown, K. W. (2005). Validation of the mindful attention awareness scale in a cancer population. Journal of Psychosomatic Research, 58(1), 29-32.

Carlson, L. E., Ursuliak, Z., Goodey, E., Angen, M. ve Speca, M. (2001). The effects of a mindfulness meditation-based stress reduction program on mood and symptoms of stress in cancer outpatients: 6-month follow-up. Supportive care in Cancer, 9(2), 112123.

Carmody, J. ve Baer, R. A. (2008). Relationships between mindfulness practice and levels of mindfulness, medical and psychological symptoms and well-being in a mindfulnessbased stress reduction program. Journal of behavioral medicine, 31(1), 23-33.

Cash, M. ve Whittingham, K. (2010). What facets of mindfulness contribute to psychological well-being and depressive, anxious, and stress-related symptomatology? Mindfulness, l(3), 177-182.

Catanzaro, S. J. ve Mearns, J. (1990). Measuring generalized expectancies for negative mood regulation: initial scale development and implications. Journal of Personality Assessment, 54, 546-563.

Cannon, W. B. (1932). The wisdom of the body. New York: Norton.

Ciesla, J. A., Reilly, L. C., Dickson, K. S., Emanuel, A. S. ve Updegraff, J. A. (2012). Dispositional mindfulness moderates the effects of stress among adolescents: rumination as a mediator. Journal of Clinical Child \& Adolescent Psychology, 41(6), 760-770.

Cohen, S., Kamarck, T. ve Mermelstein, R. (1983). A global measure of perceived stress. Journal of Health and Social Behavior, 24, 385-396.

Colle, K. F. F., Vincent, A., Cha, S. S., Loehrer, L. L., Bauer, B. A. ve Wahner-Roedler, D. L. (2010). Measurement of quality of life and participant experience with the mindfulnessbased stress reduction program. Complementary Therapies in Clinical Practice, 16(1), $36-40$. 
Çatak, P. D. ve Ögel, K. (2010). Farkındalık temelli terapiler ve terapötik süreçler. Klinik Psikiyatri, 13, 85-91.

Çatalsakal, S. (2016). Bilinçli farkındalı̆̆ın iş performansı ve iş doyumu ile iliş̧kisi: Özdüzenlemenin aracı değişken olarak rolü (Yayımlanmamış yüksek lisans tezi). Orta Doğu Teknik Üniversitesi, Ankara.

De Lissnyder, E., Koster, E. H., Goubert, L., Onraedt, T., Vanderhasselt, M. A. ve De Raedt, R. (2012). Cognitive control moderates the association between stress and rumination. Journal of Behavior Therapy and Experimental Psychiatry, 43(1), 519-525.

Demir, V. (2014). Bilinçli farkındalık temelli hazırlanan eğitim programının bireylerin depresyon ve stres düzeyleri üzerine etkisi (Yayımlanmamış yüksek lisans tezi). Arel Üniversitesi, İstanbul.

Deyo, M., Wilson, K. A., Ong, J. ve Koopman, C. (2009). Mindfulness and rumination: Does mindfulness training lead to reductions in the ruminative thinking associated with depression? The Journal of Science and Healing, 5(5), 265-271.

Dodge, K. A. (1991). The structure and function of reactive and proactive aggression. Toronto: Lawrence Erlbaum Associates, Inc.

Ekblad, A. G. (2008). Effects of mindfulness training on emotional regulation and attention (Yayımlanmamış doktora tezi). Duke University, Durham.

Eker, İ. (2016). Travmatik yaşantıların pskolojik sağllğa etkisi: travmanın türü, zaman yönelimi, dünyaya ilişkin varsayımlar ve ruminasyonlar açısından bir inceleme (Yayımlanmamış yüksek lisans tezi). Ankara Üniversitesi, Ankara.

Ercan, B. (2015). Strese yatkınlık, bilişsel duygu düzenleme ve ebeveynlik biçiminin obsesif inançlar üzerine etkisi (Yayımlanmamış yüksek lisans tezi). Uludağ Üniversitesi, Bursa.

Falkenström, F. (2010). Studying mindfulness in experienced meditators: a quasiexperimental approach. Personality and Individual Differences, 48, 305-310.

Garnefski, N., Kraaij, V. ve Spinhoven, P. (2001). Negative life events, cognitive emotion regulation and emotional problems. Personality and Individual Differences, 30(8), 1311-1327.

Giluk, T. L. (2009). Mindfulness, big five personality, and affect: A meta-analysis. Personality and Individual Differences, 47, 805-811.

Goldin, P. R. ve Gross, J. J. (2010). Effects of mindfulness-based stress reduction (mbsr) on emotion regulation in social anxiety disorder. Emotion, 10(1), 83.

Gross, J. J. (1998). Antecedent-and response-focused emotion regulation: divergent consequences for experience, expression, and physiology. Journal of Personality and Social Psychology, 74(1), 224.

Grossman, P., Niemann, L., Schmidt, S. ve Walach, H. (2004). Mindfulness-based stress reduction and health benefits: A meta-analysis. Journal of Psychosomatic Research, 57(1), 35-43.

Gündüz, H. (2016). Yetişkinlerde bilinçli farkındalık (mindfulness) ve duygu düzenleme arasındaki ilişki (Yayımlanmamış yüksek lisans tezi). Nişantaşı Üniversitesi, İstanbul.

Hayes, A. F. (2013). Introduction to mediation, moderation, and conditional process analysis: A regression-based approach. New York: Guilford Press.

Hayes, S. C. (2004). Acceptance and commitment therapy, relational frame theory, and the third wave of behavioral and cognitive therapies. Behavior Therapy, 35(4), 639-665.

Howell, A. J., Digdon, N. L. ve Buro, K. (2010). Mindfulness predicts sleep-related selfregulation and well-being. Personality and Individual Differences, 48(4), 419-424.

Jacobsen, P. ve diğerleri. (2011). Mindfulness groups for psychosis; key issues for implementation on an inpatient unit. Behavioural and Cognitive Psychotherapy, 39(03), 349-353.

Jain, S., Shapiro, S. L., Swanick, S., Roesch, S. C., Mills, P. J., Bell, I. ve Schwartz, G. E. (2007). A randomized controlled trial of mindfulness meditation versus relaxation training: Effects on distress, positive states of mind, rumination, and distraction. Annals of Behavioral Medicine, 33(1), 11-21. 
Kabat-Zinn, J. (1982). An outpatient program in behavioral medicine for chronic pain patients based on the practice of mindfulness meditation: Theoretical considerations and preliminary results. General Hospital Psychiatry, 4(1), 33-47.

Kabat-Zinn, J. (2003). Mindfulness based interventions in context: Past, present and future. Clinical Psychology Science Practice, 10, 144-156.

Kabat-Zinn, J. (2009). Full catastrophe living: Using the wisdom of your mind and body to face stress, pain, and illness. New York: Delacorte.

Karatepe, H. T., Yavuz, F. K. ve Türkcan, A. (2013). Ruminatif Düşünme Biçimi Ölçeği'nin Türkçe geçerlilik ve güvenilirliği. Klinik Psikofarmakoloji Bülteni-Bulletin of Clinical Psychopharmacology, 23(3), 231-41.

Kim, Y. W., Lee, S. H., Choi, T. K., Suh, S. Y., Kim, B., Kim, C. M., Cho, S. J., Kim, M. J., Yook, K., Ryu, M., Song, S. K. ve Ki-Hwan, Y. (2009). Effectiveness of mindfulness-based cognitive therapy as an adjuvant to pharmacotherapy in patients with panic disorder or generalized anxiety disorder. Depression and Anxiety, 26(7), 601-606.

Kocaefe, T. (2013). Özerklik veren ebeveynlik stili, bilinçli farkındalık seviyesi ve psikolojik sağllk arasındaki ilişki (Yayımlanmamış yüksek lisans tezi). İstanbul Bilgi Üniversitesi, İstanbul.

Koole, S. L. (2009). The psychology of emotion regulation: An integrative review. Cognition and Emotion, 23(1), 4-41.

Kristeller, J. L. ve Wolever, R. Q. (2010). Mindfulness-based eating awareness training for treating binge eating disorder: The conceptual foundation. Eating Disorders, 19(1), 4961.

Lazarus, R. S. ve Folkman, S. (1984). Stress, appraisal and coping. NewYork: Springer.

Leigh, J., Bowen, S. ve Marlatt, G. A. (2005). Spirituality, mindfulness and substance abuse. Addictive Behaviors, 30(7), 1335-1341.

Lykins, E. L. ve Baer, R. A. (2009). Psychological functioning in a sample of long-term practitioners of mindfulness meditation. Journal of Cognitive Psychotherapy, 23(3), 226-241.

Martin, L. ve Tesser, A. (1996). Ruminative thoughts, advances in social cognition, Hillsdale: Erlbaum.

Mezo, P. G. ve Baker, R. M. (2012). The moderating effects of stress and rumination on depressive symptoms in women and men. Stress and Health, 28(4), 333-339.

Michalak, J., Hölz, A. ve Teismann, T. (2011). Rumination as a predictor of relapse in mindfulness-based cognitive therapy for depression. Psychology and Psychotherapy: Theory, Research and Practice, 84(2), 230-236.

Miller, J. J., Fletcher, K. ve Kabat-Zinn, J. (1995). Three- years follow up and clinical implications of a mindfulness meditation- based stress reduction in the treatment of anxiety disorders. General Hospital Psychiatry, 17(3), 192- 200.

Morgan, D. (2003). Mindfulness-based cognitive therapy for depression: a new approach to preventing relapse. Psychotherapy Research, 13(1), 123-125.

Neff, K. (2003). Self-compassion: an alternative conceptualization of a healthy attitude toward oneself. Self and Identity, 2(2), 85-101.

Nolen-Hoeksema, S., Wisco, B. E. ve Lyubomirsky, S. (2008). Rethinking rumination. Perspectives on Psychological Science, 3(5), 400-424.

Ott, M. J., Norris, R. L. ve Bauer-Wu, S. M. (2006). Mindfulness meditation for oncology patients: A discussion and critical review. Integrative Cancer Therapies, 5(2), 98-108.

Ögel, K. (2012). Farkındalık (ayrımsama) ve kabullenme temelli terapiler. Ankara: HYB Basım Yayin.

Özyeşil, Z. (2011). Üniversite ögrrencilerinin öz-anlayış düzeylerinin bilinçli farkındalık kişilik özellikleri ve bazı değişkenler açısından incelenmesi (Yayımlanmamış doktora tezi). Selçuk Üniversitesi, Konya.

Özyeşil, Z., Arslan, C., Kesici, Ş. ve Deniz, M. E. (2011). Bilinçli Farkındalık Ölçeği'ni Türkçeye uyarlama çalışması. Eğitim ve Bilim, 36(160), 224-235. 
Palmer, A. ve Rodger, S. (2009). Mindfulness, stres and coping among university students. Canadian Journal of Counselling, 43(3), 198- 212.

Papageorgiou, C. ve Wells, A. (2004). Depressive rumination: Nature, theory, treatment. Chichester: Wiley.

Preacher, K. J. ve Hayes, A. F. (2008). Asymptotic and resampling strategies for assessing and comparing indirect effects in multiple mediator models. Behavior Research Methods, 40(3), 879-891.

Raes, F. ve Williams, J. M. G. (2010). The relationship between mindfulness and uncontrollability of ruminative thinking. Mindfulness, 1(4), 199-203.

Ramel, W., Goldin, P. R., Carmona, P. E. ve McQuaid, J. R. (2004). The effects of mindfulness meditation on cognitive processes and affect in patients with past depression. Cognitive Therapy and Research, 28(4), 433-454.

Roemer, L., Lee, J. K., Salters-Pedneault, K., Erisman, S. M., Orsillo, S. M. ve Mennin, D. S. (2009). Mindfulness and emotion regulation difficulties in generalized anxiety disorder: Preliminary evidence for independent and overlapping contributions. Behavior Therapy, 40(2), 142.

Roger, D. ve Hudson, C. (1995). The role of emotion control and emotional rumination in stress management training. International Journal of Stress Management, 2(3), 119-132.

Sears, S. ve Kraus, S. (2009). I think therefore I am: Cognitive distortions and coping style as mediators for the effects of mindfulness meditation on anxiety, positive and negative affect, and hope. Journal of Clinical Psychology, 65(6), 561- 573.

Selye, H. (1956). The stress of life. NewYork: McGraw-Hill.

Smith, J. M. ve Alloy, L. B. (2009). A roadmap to rumination: A review of the definition, assessment, and conceptualization of this multifaceted construct. Clinical Psychology Review, 29(2), 116-128.

Şahin, N. H. (1994). Stresle başa çıkma: Olumlu bir yaklaşım. Ankara: Türk Psikologlar Derneği Yayınları.

Taku, K., Cann, A., Tedeschi, R. G. ve Calhoun, L. G. (2009). Intrusive versus deliberate rumination in posttraumatic growth across us and Japanese samples. Anxiety, Stres, \& Coping, 22(2), 129-136.

Thomsen, D. K. (2006). The association between rumination and negative affect: A review. Cognition \& Emotion, 20(8), 1216-1235.

Thompson, R. A. (1994). Emotion regulation: A theme in search of definition. Monographs of the Society for Research in Child Development, 59(2-3), 25-52.

Ülev, E. (2014). Üniversite ögrencilerinde bilinçli farkındalık düzeyi ile stresle başa çıkma tarzının depresyon, kaygl ve stres belirtileriyle ilişkisi (Yayımlanmamış yüksek lisans tezi). Hacettepe Üniversitesi, Ankara.

Vøllestad, J., Sivertsen, B. ve Nielsen, G. H. (2011). Mindfulness based stres reduction for patients with anxiety disorders: Evolution in a randomized controlled trial. Behavior Research and Therapy, 49, 281-288.

Vujanovic, A. A., Youngwirth, N. E., Johnson, K. A. ve Zvolensky, M. J. (2009). Mindfulnessbased acceptance and posttraumatic stress symptoms among trauma-exposed adults without axis i psychopathology. Journal of Anxiety Disorders, 23(2), 297-303.

Vujanovic, A. A., Zvolensky, M. J., Bernstein, A., Feldner, M. T. ve McLeish, A. C. (2007). A test of a interactive effects of anxiety sensitivity and mindfulness in the prediction of anxious body vigilance. Behaviour Research and Therapy, 45, 1393-1400.

Wang, M. ve Saudino, K. J. (2011). Emotion regulation and stress. Journal of Adult Development, 18(2), 95-103.

Watkins, E. R. (2008). Constructive and unconstructive repetiteve thought. Psychological Bulletin, 134(2), 163-206.

Weinstein, N., Brown, K. W. ve Ryan, R. M. (2009). A multi-method examination of the effects of mindfulness on stress attribution, coping, and emotional well-being. Journal of Research in Personality, 43(3), 374-385. 
Wilkinson, P. O., Croudace, T. J. ve Goodyer, I. M. (2013). Rumination, anxiety, depressive symptoms and subsequent depression in adolescents at risk for psychopathology: A longitudinal cohort study. BMC Psychiatry, 13(1), 250.

Wupperman, P., Neumann, C. S. ve Axelrod, S. R. (2008). Do deficits in mindfulness underlie borderline personality features and core difficulties? Journal of Personality Disorders, 22(5), 466-482.

Yerlikaya, E. E. (2009). Üniversite ögrencilerinin mizah tarzları ile algılanan stres, kaygı ve depresyon düzeyleri arasındaki ilişkinin incelenmesi (Yayımlanmamış doktora tezi). Çukurova Üniversitesi, Adana.

Yerlikaya, E. E. ve İnanç, B. (2007). Algılanan stres ölçeğinin türkçe çevirisinin psikometrik özellikleri. İzmir: IX. Ulusal Psikolojik Danışma ve Rehberlik Kongresi.

Yılmaz, E. (2016). Şizofreni hastalarında farkındalık temelli psikososyal beceri eğitiminin işlevsel iyileşme ve içgörü düzeyine etkisi (Yayımlanmamış doktora tezi). Atatürk Üniversitesi, Erzurum.

Zeidan, F., Gordon, N. S., Merchant, J. ve Goolkasian, P. (2010). The effects of brief mindfulness meditation training on experimentaly induced pain. The Journal of Pain, $11(6), 505-521$.

\section{Extended Abstract}

\section{Introduction}

Stress is the cognitive, mental or physical reactions that occur as a result of real or perceived stimuli that affect the equilibrium state of the individual by coming from the inside or the outside (Budak, 2001). In recent years, it has come to the fore that the effects of stress vary depending on the perception of the person (Yerlikaya \& İnanç, 2007). This perspective brings out the perceived stress concept (Cohen, Kamarck \& Mermelstein, 1983). In this context, dealing with perceived stress has become an important issue.

One of the prominent concepts related to coping with perceived stress is mindfulness (Kabat-Zinn, 2009). Research has supported this point of view and revealed that mindfulness has an important effect on coping with stress (Miller, Fletcher \& Kabat-Zinn, 1995; Carmody \& Baer, 2008). When the literature is examined, it is seen that other concepts related to stress and mindfulness are rumination and negative mood regulation. There are many studies that show both factors in relation to stress and mindfulness (Giluk, 2009; Jain, Shapiro, Swanick, Roesch, Mills, Bell \& Schwartz, 2007; Raes \& Williams, 2010; Ramel, Goldin, Carmona \& McQuaid, 2004).

The study aims to examine the mediatory role of rumination and negative mood regulation in the relationship between mindfulness and perceived stress among university students. For this purpose, this study had two objectives: (1) to examine the relationship between mindfulness, perceived stress, rumination, and negative mood regulation in a sample of university students and (2) to examine the role of rumination and negative mood regulation as a mediator of mindfulness and perceived stress in this group.

\section{Method}

The study sample consisted of 745 university students, 425 of whom were female (57\%) and 320 of whom were male (43\%). The age average of the participant students is $21.64(\mathrm{Sd}=2.77)$. The Mindful Attention Awareness Scale (Brown \& Ryan, 2003), Perceived Stress Scale (Cohen, Kamarck \& Mermelstein,1983), Ruminative Thought Style Questionnaire (Brinker \& Dozois, 2009) and The Negative Mood Regulation Scale (Catanzaro \& Mearns, 1990) were used in the study. The application of the scales took 20 minutes and was performed in class under the supervision of the researchers.

For mediatory analysis, a regression-oriented mediatory macro technique was employed. Both Sobel $\mathrm{Z}$ and bootstrapping procedures were applied to analyze the significance of indirect effects. Data analysis was carried out through SPSS 21.00 statistical package programme. Statistical significance has been accepted as $p<.05$. 


\section{Result and Discussion}

To examine the relations between mindfulness, perceived stress, rumination, and negative mood regulation, we computed Pearson correlations between all of the study measures. Scores on mindfulness were found to be significantly correlated with perceived stress, rumination and with negative mood regulation. Scores on perceived stress and rumination were found negatively correlated with mindfulness scores (respectively $\mathrm{r}=-.43$ and $\mathrm{r}=-.38$ ), but positively correlated with negative mood regulation scores $(\mathrm{r}=.41)$. Additionally, perceived stress scores were found to be significantly associated with scores on rumination $(\mathrm{r}=.43)$ and negative mood regulation scores $(\mathrm{r}=-.52)$.

The study results related to Sobel $\mathrm{Z}$ and bootstrapping procedures demonstrated that both rumination $(\mathrm{Z}=-6.99, \mathrm{p}<.001$, Bootstrap coefficient $=-.06, \mathrm{Sh}=.01,95 \% \mathrm{GA}=-.09,-04)$ and negative mood regulation $(\mathrm{Z}=-6.99, \mathrm{p}<.001$, Bootstrap coefficient $=-.09, \mathrm{Sh}=.01,95 \%$ $\mathrm{GA}=-.12,-07)$ partially played a mediatory role in the relationship between mindfulness and perceived stress.

The results indicated that the mindfulness was positively correlated with the rumination, but negatively correlated with the perceived stress. The rumination was positively correlated with the perceived stress. These results are consistent with earlier studies reporting a relationship between perceived stress and rumination (Alloy etc., 2000; De Lissnyder etc., 2012; Mezo \& Baker, 2012; Roger \& Hudson, 1995; Smith \& Alloy, 2009) and mindfulness (Cash \& Whittingham, 2010; Weinstein, Brown, \& Ryan, 2009; Ülgev, 2014). Additionally, the results indicated that the mindfulness was negatively correlated with the negative mood regulation and the perceived stress. The negative mood regulation was positively correlated with the perceived stress. These results are consistent with earlier studies reporting a relationship between perceived stress and negative mood regulation (Ekbland, 2008; Koole, 2009; Wang \& Saudino, 2011). The results showed that the rumination and negative mood regulation partially mediated the relationship between mindfulness and perceived stress. In other words, as mindfulness increases, perceived stress decreases, and rumination and negative mood regulation plays a mediating role in this decrease.

There are some limitations in this study. Firstly, all of the data were collected from university students living in one city in Turkey, which limits the generalizability of the current findings. Secondly, the data in this research was collected by self-report scales, which have some potential response misrepresentations. Despite its limitations, the current study presents a significant contribution to the existing literature about perceived stress and related factors on university students. In the context of university counseling services, the role of rumination and negative mood regulation must be taken into consideration and psycho-educational programs should consider the effects of this variable on perceived stress. 